\title{
Structural Origin of Surface Transformations in Arsenic Sulfide Thin Films upon UV-Irradiation
}

\author{
Andriy Kovalskiy ${ }^{1 *}$, Miroslav Vlcek ${ }^{2}$, Karel Palka ${ }^{2,3}$, Jan Buzek ${ }^{3}$, James York-Winegar ${ }^{1}$, Justin \\ Oelgoetz $^{1}$, Roman Golovchak ${ }^{1}$, Oleh Shpotyuk ${ }^{4,5}$, Himanshu Jain ${ }^{6}$ \\ ${ }^{1}$ Department of Physics \& Astronomy, Austin Peay State University, 601 College St., Clarksville, TN \\ 37044, USA \\ ${ }^{2}$ Center of Materials and Nanotechnologies, Faculty of Chemical Technology, University of Pardubice, \\ nam. Cs. Legii 565, 53002 Pardubice, Czech Republic \\ ${ }^{3}$ Department of General and Inorganic Chemistry, Faculty of Chemical Technology, University of \\ Pardubice, Studentska 573, 53210 Pardubice, Czech Republic \\ ${ }^{4}$ Vlokh Institute of Physical Optics, 23 Dragomanov str., Lviv 79005, Ukraine \\ ${ }^{5}$ Institute of Physics of Jan Dlugosz University, 13/15 al. Armii Krajowej, Czestochowa PL-42201, \\ Poland \\ ${ }^{6}$ Department of Materials Science \& Engineering, Lehigh University, 5 East Packer Ave., Bethlehem, PA \\ 18015, USA
}

\footnotetext{
* Corresponding Author. Tel. +1 9312216157

E-mail: kovalskiya@apsu.edu (A. Kovalskiy)
} 
graphical abstract

$$
\mathrm{As}_{4} \mathrm{~S}_{3}+\mathrm{As}_{4} \mathrm{O}_{6}
$$

\section{UV}

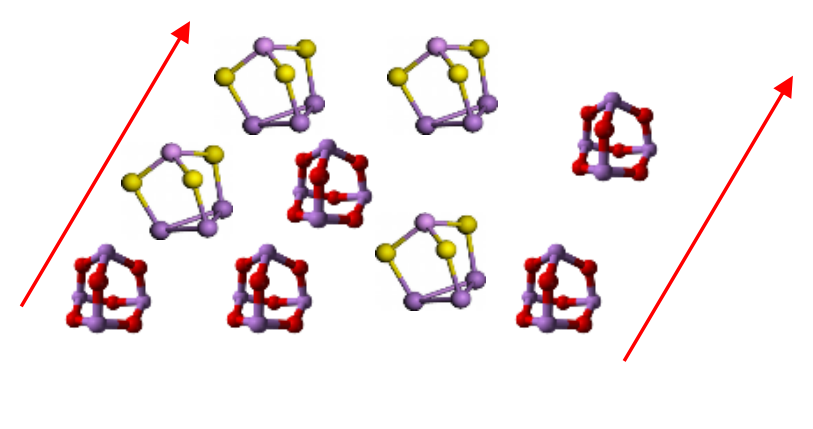

$\mathrm{As}_{2} \mathrm{~S}_{3}$ 


\begin{abstract}
Photostructural transformations within $A s_{x} S_{100-x}(x=30,33,35,40)$ thin films upon exposure to LED light of different wavelengths, in both air and argon environments have been studied by high resolution XPS, Raman spectroscopy and LEIS methods. These complementary results show that light of energies close to the band gap does not modify chemical composition of the surface, but induces simple photopolymerization reactions. Superbandgap UV light, however, significantly increases $S / A s$ ratio on the surface due to formation of $S$-rich layer under both environmental conditions. It is proposed that photovaporization of both oxide and non-oxide cage-like molecules is responsible for the observed effect.
\end{abstract}

Keywords: Chalcogenide glasses; Photoinduced effects; X-ray photoelectron spectroscopy; Thin films; Surface composition

\title{
1. Introduction
}

Photoinduced effects in thermally-deposited chalcogenide glass $(\mathrm{ChG})$ thin films have been studied for over two decades and serve as a basis for many uses of these materials in photonics, optoelectronics, information technologies and other fields [1-4]. The most prominent photostructural and optical effects in $\mathrm{ChG}$ thin films are caused by exposure to the bandgap radiation [5-8]. Higher energy superbandgap light, which is primarily absorbed within the very top layer of the film, can also influence optical properties and simultaneously modify the surface structure significantly [9,10]. As an example, in 1989 Kolobov et al. [9] found that UV irradiation of $A s_{40} S_{60}$ (bandgap $E_{g} \approx 2.35 \mathrm{eV}$ or equivalently $525 \mathrm{~nm}$ ) considerably changes properties of the surface and decreases sticking ability of $\mathrm{Zn}$ and $\mathrm{Cd}$ films deposited on top of ChG thin layers. At the same time, no surface depletion of $S$ or $A s$ was detected. Their samples were irradiated with a broad spectrum of light from a mercury lamp that provided limited control of exposure parameters. Based on X-ray photoelectron spectroscopy (XPS) data the observed effects were explained exclusively by the surface oxidation of $A s$-rich structural fragments. In contrast, Janai [11] proposed light-enhanced vaporization of arsenic oxide and molecular sulphur from the surface of $\mathrm{As}_{2} \mathrm{~S}_{3}$ thin films under UV exposure of different intensity with the energy threshold near $2.5 \mathrm{eV}$, which corresponds to $495 \mathrm{~nm}$. Finally, in 1999, Keji Tanaka [12] observed structural photodepression with the estimated thinning rate close to $10^{-3} \AA / \mathrm{s}$ under UV irradiation with moderate intensity source $\left(\sim 10 \mathrm{~mW} / \mathrm{cm}^{2}\right)$ in $50 \mu \mathrm{m}$ thick $A s_{2} S_{3}$ films. This observation runs contrary to the usually reported giant photoexpansion upon irradiation by bandgap $(0.4 \%$ of the 
initial volume) or sub-bandgap light (4\% of the initial volume). This photodepression was ascribed to the photovaporization of $A s$ oxide and sulphur from the surface at room temperature, but the most pronounced changes started to be observed only upon irradiation with light close to $3.0 \mathrm{eV}$ (i.e. $415 \mathrm{~nm}$ ). Photoinduced diffusion has been considered in literature as an additional probable mechanism for surface modifications of $\mathrm{ChG}$ thin films under light exposure [13]. Thus there are a variety of observations and mechanisms reported in the literature, often inconsistent with each other. Recent advances in characterization techniques provide opportunity to investigate more precisely the structure of $\mathrm{ChG}$ thin film in relation to irradiation conditions, and thus to explain discrepancies between the results of different authors.

In our previous work [14] we found using high resolution XPS that exposure of $A s_{40} S_{60}$ thin film in air with superbandgap LED light causes formation of $S$-rich surface layer. However, to clarify if reaction with oxygen affects the mechanism of photostructural transformations, a similar experiment in argon atmosphere should be performed and compared. It would establish whether surface oxidation is the only source of surface decomposition of $\mathrm{ChG}$ thin films or other molecular rearrangements are also involved in this process.

In this paper we analyze using XPS the products of photostructural transformations at the surface of $A s_{x} S_{100-x}(x=30,33,35,40)$ thin films irradiated in argon atmosphere $(99.996$ vol. \% purity) with non-polarized LED light of different wavelengths (centered at $375 \mathrm{~nm}, 405 \mathrm{~nm}, 450$ $\mathrm{nm}$ and $525 \mathrm{~nm})$ and constant power $\left(\sim 100 \mathrm{~mW} / \mathrm{cm}^{2}\right)$ and compare with previous results with those on the $A s_{40} S_{60}$ films irradiated in air [14]. Application of high resolution low energy ion scattering (LEIS) technique, one of the most sensitive methods for compositional analysis of the top most surface layers [15], is exploited to confirm or exclude diffusion contribution to the photostructural transformations on the surface of $\mathrm{ChG}$ thin films. The obtained results are supported by structural models for over-stoichiometric molecular clusters in $A s-S$ system.

\section{Materials and Methods}

To prepare bulk ChG used as source materials for thermal deposition, high purity (5N) elemental powders were melted in an evacuated quartz ampoules for $24 \mathrm{hrs}$ with final stage of high temperature synthesis for $8 \mathrm{hrs}$. at temperatures not higher than $900^{\circ} \mathrm{C}$ (depending on chemical composition) in a rocking furnace; the melt was quenched in cold water.

Two sets of the ChG thin films were prepared by conventional vacuum thermal deposition technique. For exposure in air, the $1000 \mathrm{~nm} A s_{40} S_{60}$ films were thermally deposited onto microscope slides (evaporator UP-858, Tesla Corporation, initial pressure $1 \times 10^{-4} \mathrm{~Pa}$ ) using planetary rotating sample holders. The deposition rate (controlled by the dynamical weighing method using a SV-1843 A MIKI-FFV system) was close to $10 \AA /$ s. The set of $A s_{x} S_{100-x}(x=30$, $33,35,40)$ thin films for exposure in argon had $200 \mathrm{~nm}$ thickness to provide sufficient penetration depth for the UV irradiation [14]. All other conditions of preparation and control were the same. Only low-level red illumination was used in the laboratory during the preparation and measurements to minimize any photoinduced effects produced by the ambient lighting.

The prepared ChG thin films were exposed to light from LEDs with peak wavelengths 375, 405, 450 or $525 \mathrm{~nm}\left(W \approx 100 \mathrm{~mW} / \mathrm{cm}^{2}\right)$ in air and argon $(99.995 \%$ pure $)$ for $60 \mathrm{~min}$. The temperature of the "substrate-thin film" thermodynamic system during irradiation was monitored using a thermocouple; no significant heating (larger than $1 \mathrm{~K}$ ) was recorded. However we can not exclude

local heating on the surface of thin films related to the dependence of optical absorption on the 
wavelength of LED light. Optical transmission spectra of the virgin and exposed thin films were recorded by a modular spectrometer (StellarNet Inc.).

Raman scattering spectra were recorded using BRUKER IFS 55 IR spectrometer with FRA 106 accessory, with $\mathrm{Nd}$ :YAG laser $(1064 \mathrm{~nm})$ as the excitation probe $(50 \mathrm{~mW}, 200$ scans, resolution 2 $\mathrm{cm}^{-1}$ ). The samples for Raman measurements were collected by scratching the thin films into specially designed sample holders.

Surface structure and composition of the virgin and irradiated ChG films were studied by highresolution XPS, which provides information from the top $\sim 10 \mathrm{~nm}$ layer with about $65 \%$ of the signal originating from the outermost $30 \AA$ of the film. The XPS spectra were recorded with a Scienta ESCA-300 spectrometer using monochromatic $A l K_{\alpha} \mathrm{X}$-rays (1486.6 eV). The surface charging from photoelectron emission was neutralized using a low energy ( $<10 \mathrm{eV})$ electron flood gun [16]. The analysis area was a spot $\sim 1 \mathrm{~mm}$ long and $\sim 250 \mu \mathrm{m}$ wide. Data acquisition was restricted electronically to a region smaller than the X-ray illuminated area. The XPS data consisted of survey scans over the entire binding energy $(B E)$ range and selected scans over the core level photoelectron peaks of interest. An energy increment of $0.05 \mathrm{eV}$ was used for recording the core level spectra. The reproducibility of the measurements was checked on different regions of the film surface, as well as on different samples. The XPS data were calibrated against impurity carbon $1 s$ line $(284.8 \mathrm{eV})$ as reference.

XPS data analysis was conducted with standard Casa-XPS software package. For analyzing the core level spectra, Shirley background was subtracted and a Voigt line shape was assumed for the peaks. Concentrations of appropriate chemical elements were determined from the area of core level peaks taking into account the experimentally determined sensitivity coefficients. Each $S 2 p$ core level spectrum and $A s 3 d$ core level spectrum included one or more spin orbit doublets consisting of $2 p_{3 / 2}$ and $2 p_{1 / 2}$ components for $S$, or $3 d_{5 / 2}$ and $3 d_{3 / 2}$ components for As. The number of doublets within a given peak was determined by an iterative curve fitting process in which a doublet was added only if it significantly improved the "goodness of fit" of the experimental data to the envelope of the fitted curve. The As $3 d_{3 / 2}$ and $A s 3 d_{5 / 2}$ peaks were forced to have a peak separation of $0.70 \mathrm{eV}$ and an area ratio of 0.7 . For $S 2 p_{3 / 2}$ and $S 2 p_{1 / 2}$ core level components were forced to have a $1.16 \mathrm{eV}$ separation and an area ratio of 0.5 . These reference values were obtained experimentally for a number of chalcogenide glasses using the same Scienta ESCA-300 spectrometer. The full width at half the maximum $(F W H M)$ of peaks was assumed to be the same for both components of a doublet. However, based on previous experience, reasonable differences between $F W H M$ values for different doublets of the same core level peak were allowed. The mix between the Gaussian and Lorentzian fractions in the Voigt function was chosen to be the same for all doublets of a given core level. With these constraints the uncertainty in the peak position $(B E)$ and area $(A)$ of each component after fitting was $\sim 0.05 \mathrm{eV}$ and $\sim 2$ at.\% for $S$ atoms and $\sim 0.1$ $\mathrm{eV}$ and $\sim 5$ at.\% for $A s$ atoms. This difference in fitting reliability for $S$ and $A s$ atoms arises from the difference in separation between the BE values of the respective components within $S 2 p$ or $A s$ $3 d$ doublets.

LEIS is a unique tool in surface analysis, which is able to provide chemical composition of the outermost atomic layer [15]. The LEIS spectra were collected using IONTOF Qtac100 spectrometer (ION-TOF GmbH). The incident ion beam was directed perpendicularly towards sample's surface; the depth profiles of composition for non-irradiated and UV irradiated ( $\lambda=375$ $\mathrm{nm}$ LED) were obtained by removing atomic layers with in situ sputtering. The typical current of 
probing $3 \mathrm{keV} \mathrm{He}^{+}$beam was $4 \mathrm{nA}$, rastered over a $750 \mu \mathrm{m}$ x $750 \mu \mathrm{m}$ area, while that of the $2 \mathrm{keV}$ $A r^{+}$beam for sputtering was $210 \mathrm{nA}$ rastered over a $1500 \mu \mathrm{m} \times 1500 \mu \mathrm{m}$ area.

\section{Theory/calculations}

To help illuminate possible schemes of structural transformations for different atomic configurations proper to binary $A s-S \mathrm{ChG}$, modest quantum chemistry calculations were also carried out. A number of cage molecules and network-forming fragments were modelled using the cation interlinking network cluster approach (CINCA) [17] and following the procedure developed for chalcogen-rich As-Se glasses [18]. Quantum-chemical calculations were performed in NWChem (v. 6.5) [19] using the 6-311G** [20-22] basis set (the largest Pople type basis set defined for $A s)$. Three levels of theory were used, the first, the restricted Hartree-Fock selfconsistent field method (RHF) [23,24] was used as it has been used in previous CINCA calculations. Additionally, we carried out density functional theory calculations using the PBE0 density functional [25], and much larger calculations using the second order Møller-Plesset perturbation theory (MP2) [26]. All calculations were carried out on optimized geometries; these results were used to calculate the change in the electronic energy $\Delta E$ of various possible decomposition pathways in order to determine which might be favorable. Vibrational energies were not included in these calculations as the CINCA framework only considers electronic contributions to a cluster's energy.

\section{Results}

Tables 1 and 2 present the area under the XPS core level $S 2 p$ and $A s 3 d$ spectra for the virgin thermally evaporated $A s_{x} S_{100-x}(x=30,33,35,40)$ films; the compositions determined from these areas correspond to the theoretical $S / A s$ ratios, within the error of the experiment $( \pm 2$ at. $\%)$. As an example, XPS spectra for the film of stoichiometric composition $A s_{40} S_{60}$ are shown in Fig. 1. The $S 2 p$ spectra presented in Fig. $1 a$ can be successfully fitted by 3 separate doublets; thus the $S$ atoms on the surface exist in 3 different chemical environments. The areas under the doublets correspond to the concentration of atoms in the appropriate chemical environments. The $S 2 p_{3 / 2}$ components for these doublets are centered at $162.5 \mathrm{eV}$ (component I), $163.1 \mathrm{eV}$ (component II) and $161.2 \mathrm{eV}$ (component III) with relative fractions of $86 \%, 10 \%$ and $4 \%$, respectively. Fitting performed on the $A s 3 d$ peak (Fig. $1 b$ ) reveals 2 chemical environments for $A s$ atoms with $A s 3 d_{5 / 2}$ components centered at $43.3 \mathrm{eV}$ (component I) and $42.8 \mathrm{eV}$ (component II) with concentrations $80 \%$ and 20 $\%$. Every virgin film exposed to air immediately after deposition experiences minor surface oxidation with content of oxygen atoms at the surface from 3 to 6 at. $\%$. The concentration of the surface oxygen in the virgin $A s_{40} S_{60} \mathrm{ChG}$ film is shown in Table 1.

Comparisons of surface compositions for stoichiometric $A s_{40} S_{60} \mathrm{ChG}$ thin film irradiated with light of different energies but constant intensity $\left(W \approx 100 \mathrm{~mW} / \mathrm{cm}^{2}\right)$ in air and argon environments are presented in Table 1. It is evident that in both atmospheres the band gap LED light $(\lambda=525$ $\mathrm{nm}$ ) does not influence chemical composition of the film surface. At the same time, higher energy exposure with $450 \mathrm{~nm}$ and, especially, $405 \mathrm{~nm}$ and $375 \mathrm{~nm}$ wavelength light leads to the formation of a $S$-rich surface layer with $S / A s$ ratio as high as 69/31 (as opposed to the initial stoichiometric ratio of 60/40). Comparison of $S 2 p$ XPS core level spectra for non-irradiated films and films irradiated in air with $525 \mathrm{~nm}$ and $375 \mathrm{~nm}$ light reveals significant modification of their shape at exposure with UV light, but relatively minor changes upon band gap light treatment (fig. 2). The 
UV irradiation leads to relative decrease of the $S 2 p_{3 / 2}$ component centered at $163.1 \mathrm{eV}$ (component II), an increase of the major component at $162.5 \mathrm{eV}$ (component I) and disappearance of the third component centered at $161.2 \mathrm{eV}$ (component III). More detailed description of XPS data for the As40 $S_{60}$ thin films irradiated in air can be found elsewhere [14]. It was also shown there that chemical environments of $A s$ atoms changes under light exposure too with the disappearance of minor component II of $A s 3 d$ (centered at $42.8 \mathrm{eV}$ in the $A s 3 d_{5 / 2}$ peak).

Table 2 presents surface composition of $A s_{x} S_{100-x}(x=30,33,35,40)$ thin films, virgin and exposed to light in argon environment under the same irradiation conditions (as for the air atmosphere) described above. A noticeable rise of $S / A s$ ratio was observed for the samples of all studied chemical compositions irradiated with $405 \mathrm{~nm}$ and $375 \mathrm{~nm}$ LED light, even for the $A s$ deficient $A s_{30} S_{70}$, but most significantly for the stoichiometric $A s_{40} S_{60}$ thin film with 68/32 final surface $S / A s$ ratio after 1 hour of exposure to the $375 \mathrm{~nm}$ LED. Exposure with $525 \mathrm{~nm}$ or $450 \mathrm{~nm}$ light does not change the surface composition significantly of any irradiated films.

Analysis of the $S 2 p$ XPS core level spectra for $A s_{40} S_{60} \mathrm{ChG}$ thin films irradiated in argon with $525 \mathrm{~nm}$ (Fig. 3b) and $375 \mathrm{~nm}$ (Fig. 3c) LEDs roughly confirm the results for the same thin films irradiated in air [14]. The area of minor $S 2 p_{3 / 2}$ doublet component centered at $163.1 \mathrm{eV}$ (component II) decreases after exposure to band gap radiation $\left(525 \mathrm{~nm} \mathrm{LED}, \sim 100 \mathrm{~mW} / \mathrm{cm}^{2}\right)$ from $10 \%$ to $5 \%$ of the entire area of the core level band; the component centered at $161.2 \mathrm{eV}$ (component III) completely disappears (fig. 3a,b). Higher energy UV light (from 375 nm LED) removes the defect-related $B E$ (component III) as well, but increases the area of the $163.1 \mathrm{eV}$ component II from $10 \%$ to $24 \%$, and additionally creates a higher $B E$ doublet at $163.5 \mathrm{eV}$ (component IV, $11 \%$ ) (Fig. 3a,c).

The $375 \mathrm{~nm}$ light irradiation also totally eliminates the lower $B E$ (component II) in the $A s 3 d$ spectrum with the $A s 3 d_{5 / 2}$ position centered at $42.8 \mathrm{eV}$ in the freshly evaporated thin film (Fig. $4 a, c)$. At the same time, the 525 LED exposure drastically decreases concentration of As atomic sites in the surface region of the film associated with this component from $20 \%$ to 5 at. \% (Fig. $4 a, b)$.

Fig. 5 presents a comparison of oxygen concentration on the surface of $A s_{40} S_{60} \mathrm{ChG}$ thin films irradiated in argon (99.995\% pure) and air atmospheres. As expected, the intensity of the $O 1 \mathrm{~s}$ XPS core level peak is not only significantly smaller for the sample irradiated in argon, but the signal is similar to the intensity of the background noise.

Raman spectra of virgin $A s_{40} S_{60}$ thin films and the ones irradiated in argon with $375 \mathrm{~nm}$ and $525 \mathrm{~nm}$ light are presented in Fig. 6. It is clear that irradiation with both bandgap and superbandgap light causes a significant blending together of the separate Raman bands visible in the spectra of the virgin sample. Minor dissimilarities exist between the spectra for the two wavelengths; the most noticeable are the differences in the intensities of Raman bands at $271 \mathrm{~cm}^{-1}$ and $363 \mathrm{~cm}^{-1}$ as well as the ratios of $222 \mathrm{~cm}^{-1}$ and $236 \mathrm{~cm}^{-1}$ peak intensities. These changes are similar to those reported in [27].

Layer by layer study of the atomic composition of UV irradiated ( $375 \mathrm{~nm}$ wavelength, 100 $\mathrm{mW} / \mathrm{cm}^{2}$ ) $A s_{40} S_{60}$ thin films by LEIS method (based on sputtering by a $2 \mathrm{keV} A r^{+}$beam) is presented in Fig. 7. Except for the expected light-induced change of $S / A s$ ratio in the very top layers, this value remains constant through the entire thickness of the film. It should be noted, however, that accurate determination of S/As ratio from LEIS results can be complicated by preferential sputtering and ion-induced mixing described recently for silicate glasses [28]. Nevertheless, it is conceivable from the obtained results (Fig. 7) that non-irradiated and irradiated 
thin films are uniform throughout the whole thickness and the S/As ratio changes occurs only at the surface, being not a result of inward diffusion.

To investigate possible mechanisms for these structural transformations, we calculated electronic energies for optimized geometries of binary $A s-S$ molecular clusters $\left(A s_{4} S_{4}\right.$ (both realgar $(\alpha / \beta)-A s_{4} S_{4}$ and pararealgar: $\left.p-A s_{4} S_{4}\right), A s_{4} S_{5}$ (uzonite), $A s_{4} S_{3}$ (dimorphite), $A s_{4} S$ (duranusite) and pure $A s_{4}$.). The cation interlinking network cluster approach (CINCA) [17] was used to calculate an electronic energy for network-bonded orpiment $\left(\mathrm{As}_{2} \mathrm{~S}_{3}\right)$ from $\mathrm{As}_{2} \mathrm{~S}_{5} \mathrm{H}_{4}$ and $\mathrm{SH}_{2}$. The calculations were carried out at the HF/6-311G**, PBE0/6-311G** and MP2/6-311G** levels of theory, the energies are presented in Table 3. Structures optimized at the MP2/6-311G** level (which are similar to the structures which result from the other methods) are depicted in Fig. 8 and corresponding calculated energies are gathered in Table 3 as is the CINCA derived energy for orpiment $\left(\mathrm{As}_{2} \mathrm{~S}_{3}\right)$. From these energies, we calculate the $\Delta E$ of the various possible decomposition pathways of As rich structures $\left(\Delta E=E_{\text {products }}-E_{\text {reactants }}\right)$. These can be found in Table 4 as $\Delta E /$ particle. Of particular note is that only 2 of the various pathways are thermodynamically favorable (only 1 in the Hartree Fock calculations).

\section{Discussion}

Our previous XPS data [14] showed that the surface structure of thermally deposited $A s_{40} S_{60}$ thin films changes under UV irradiation $\left(1 \mathrm{~h}, \sim 100 \mathrm{~mW} / \mathrm{cm}^{2}, 405 \mathrm{~nm}\right.$ or $375 \mathrm{~nm}$ LEDs, in an air atmosphere) to resemble that of a $S$-rich $A s_{30} S_{70}$ composition. The proposed mechanism of such surface transformations relied on photo-induced vaporization of cage-like molecules such as $A s_{4} O_{6}, A s_{4} S_{4}$ or $A s_{4} S_{3}$; photo-vaporization of $A s$ and $S$ atoms from the surface of $A s$-based $C h G$ under superbandgap light at room temperature had been previously claimed $[11,12]$. In the case of As of it was exclusively related to oxide complexes, one would expect that non-oxide $A s$-rich realgar- (pararealgar-) or dimorphite-type molecules should participate in this process even in an oxygen-free neutral atmosphere such as the $99.995 \%$ Ar atmosphere used in this study. Examining this hypothesis is one of the goals of this study.

First, it is important to establish the quality and chemical structure of the thermally deposited reference thin films. The $S / A s$ ratio determined with high-resolution XPS for the near surface layers of freshly deposited non-irradiated $A s_{x} S_{100-x}(x=30,33,35,40)$ thin films and (within 2 at. $\%$ accuracy) agrees well with the respective formula compositions (Tables 1,2). As an example, we examine, in detail, the chemical structure of the surface of the As40 $S_{60}$ thin films.

The fits of the $S 2 p$ and $A s 3 d$ core level spectra and analysis of chemical shift of the fitting components (Fig. 1) show that the film contains $S$ atoms in 3 chemical environments; a majority of $S$ atoms $(\sim 86 \%)$ are in $A s-S$-As fragments (like within corner-shared $A s S_{3 / 2}$ pyramidal units of the glass network). Additionally, $\sim 10 \%$ of $S$ atoms exist in $A s-S-S$ units and the remaining $\sim 4 \%$ are recognized as 1-fold coordinated (surface) defects. Fits of the $A s 3 d$ XPS spectra shows that $\sim 80 \%$ of $A s$ atoms are in the pyramidal $A s S_{3 / 2}$ units while the rest, most probably, involve homopolar $A s-A s$ bonds. These results are in good agreement with our previous analysis of XPS spectra for thermally evaporated $A s_{40} S_{60}$ thin films [29]. Similar structural analysis was performed for a number of chemical compositions of the freshly deposited $A s_{x} S_{100-x}(x=30,33,35,40)$ thin films but extensive analysis for all other compositions is the topic for a separate publication.

Even though the photoinduced surface transformations are observed upon used irradiation conditions in the thin films of all investigated compositions, the stoichiometric $A s_{40} S_{60}$ thin films have been chosen as a model object of our studies of the changes in argon atmosphere. The 
structure of the $S 2 p$ XPS core level spectrum of these films changes noticeably after irradiation with bandgap light $(\lambda=525 \mathrm{~nm})$. The concentration of $S$ atoms in $A s-S$-S structural fragments decreases from 10 to $5 \%$ and the component associated with surface defects completely disappears, suggesting a partial photoinduced "healing" (restoration of chemical order character for bulk glass) of the surface structure (Fig. $3 a, b$ ). Here the number of $S$ atoms within the cornershared pyramidal $A s S_{3 / 2}$ units increases significantly from 86 to $95 \%$. Bandgap light exposure also causes a dramatic decrease in the number of $A s$ atoms in homopolar $A s-A s$ (sometimes called 'wrong') bonds from 20 to $5 \%$ (Fig. 4a,b). All these transformations by bandgap irradiation are not accompanied by any evident change of chemical composition of the surface.

The fact that the chemical composition of the surface of $A s_{x} S_{100-x}$ thin films does not change upon irradiation with band gap light is in good agreement with the commonly accepted concept of photoinduced structural transformations (which include both reversible and irreversible components) in thin layers of $\mathrm{ChG}$ exposed to low and moderate intensity radiation with partial restoration of chemical order typical for the bulk glasses. The possible mechanisms of such photoinduced structural effects in $\mathrm{ChG}$ thin films were presented by different authors in numerous publications [1,3,5,30-33]. Based on our XPS data the surface structure of the exposed films can be largely thought of as a network which contains $A s S_{3 / 2}$ pyramids linked through fragments containing $A s$ - $A s$ or/and $S$-S homopolar bonds. Comparison of the Raman spectra of non-irradiated and irradiated thin films (Fig. 6) confirms that the irreversible polymerization occurs upon irradiation (by both band gap and superbandgap light) of thermally deposited thin films even when the surface composition changes during irradiation. The Raman spectra of both irradiated samples are very close to that of the typical spectra for bulk arsenic sulfide glasses [27]. The peaks in the spectrum of non-irradiated thin films are much narrower in the region $100-400 \mathrm{~cm}^{-1}$ confirming the existence of distinct $A s$-rich molecular fragments such as $A s_{4} S_{4}, A s_{4} S_{3}$.

On the other hand, exposure of the $A s_{40} S_{60}$ thin films in argon to the $375 \mathrm{~nm}$ superbandgap light creates completely new doublet in $S 2 p$ spectrum, which is absent in non-irradiated samples. Its main $2 p_{3 / 2}$ component (IV, centered at $163.5 \mathrm{eV}$ ) can be associated with $S-S$-S fragments at the surface of the film (Fig. $3 c$ ). The higher binding energy of this component is related to the higher electronegativity of $S$ in comparison with $A s$ atoms; this is analyzed in detail and discussed in our previous work on glassy $A s-S$ systems [34]. UV light also totally removes defect-related component (III, centered at $161.2 \mathrm{eV}$ ) (Fig. 3a) and increases concentration of $A s-S$-S fragments linked with the $163.1 \mathrm{eV}$ peak (II). The $A s 3 d$ core level spectrum for the UV irradiated film contains only one doublet, representing $A s$ atoms within $A s S_{3 / 2}$ pyramids (Fig. $4 a, c$ ). These XPS results are in complete agreement with the observed change of the surface composition of thermally evaporated $A s_{40} S_{60}$ thin films under $375 \mathrm{~nm}$ light exposure. When one looks at the $S / A s$ ratio, it increases from 60/40 to 68/32; UV irradiation (with $375 \mathrm{~nm}$ light) of the surface of $A s_{40} S_{60}$ thin film in argon also leads to the formation of $S$-rich layer just as was previously determined thin films irradiated in an oxygen-containing environment (Table 1, Fig. 2) [14]. It should be also mentioned that a comparison of oxygen content in the thin films irradiated with the $375 \mathrm{~nm}$ light in both air and argon environments (Fig. 5) excludes dominant role of arsenic oxides in the photovaporization in argon.

In the previous studies [11,12], photovaporization of volatile cage-like $A s_{4} \mathrm{O}_{6}$ and gaseous $S_{2}$ molecules without change of $S / A s$ ratio was considered as the principal mechanism of surface decomposition of $A s-S$ binary thin films upon UV exposure. This mechanism was proposed for both high intensity [11] and low intensity [12] UV radiation. The present data about the formation of almost identical $S$-rich surface layers after $375 \mathrm{~nm}$ light irradiation in both oxygen and argon 
atmospheres support our previous argument that $A s$-rich cage molecules such as $A s_{4} S_{3}$ and possibly also heavier $A s_{4} S_{4}$ are removed from the surface along with $A s_{4} O_{6}$ molecules. It is expected that on the surface of non-polymerized $A s_{40} S_{60}$ thin films most of the cage molecules are connected with other structural units only by weak van der Waals forces. The local surface thermalization of superbandgap optical energy is considered responsible for the photovaporization of cage molecules.

There are additional indications of the participation of non-oxide cage molecules in UV-induced photovaporization process. It is known $[11,30,35,36]$ that there are two possible ways of surface decomposition of $\mathrm{ChG}$ via participation of $\mathrm{As}_{4} \mathrm{O}_{6}$ cage molecules under light exposure: photovaporization (or volatilization) and formation of microcrystals on the surface of thin films. The specific conditions for realization of each of these scenarios are still unclear and might be effected by such variables as light wavelength, intensity, humidity conditions, etc. It should be noted that the formation of dimorphite $A s_{4} S_{3}$ microcrystals on the surface of $A s_{40} S_{60}$ thin films has been reported [37]. In a manner analogous to arsenic oxide we believe that when conditions for accumulation of dimorphite molecules are not met, these cage molecules are photovaporized from the surface. Another indication in favor of our hypothesis is a relative decrease in the intensity of $A s_{4} S_{3}$ related Raman peak at $271 \mathrm{~cm}^{-1}$ after exposure to superbandgap light in comparison to bandgap irradiation (Fig. 6). This tells us that UV radiation stimulates disappearance of $A s_{4} S_{3}$ molecules.

Returning to the irradiation in air, another channel to the formation of $S$-rich surface layer in UV-exposed arsenic sulphide thin films is plausible based on photoreaction reported in [38] for single crystals belonging to the $\beta-A s_{4} S_{4}-A s_{8} S_{9}$ series:

$$
5 \mathrm{As}_{4} \mathrm{~S}_{4}+3 \mathrm{O}_{2} \rightarrow 4 \mathrm{As}_{4} \mathrm{~S}_{5}+2 \mathrm{As}_{2} \mathrm{O}_{3}
$$

The final As-rich product molecules are then evaporated from the surface of the thin film. This transformation indicates that the $A s_{4} S_{4}$ molecule is able to incorporate oxygen and restructure to As $4 S_{5}$ upon exposure to light.

One more possible mechanism of the observed change in surface $S / A s$ ratio is photoinduced diffusion. To check this possibility we investigated the composition as a function of depth by the high sensitivity LEIS method for non-irradiated and UV irradiated $(\lambda=375 \mathrm{~nm})$ thin films. The data shown in Fig. 7 clearly supports our conclusion that photovaporization is the dominant mechanism for the observed changes.

The present results also support the conclusions of Ke. Tanaka [13] that photovaporization could be the primary mechanism by which UV exposure creates photodepressions in $A s_{40} S_{60}$ thin films; this runs contrary to the giant photoexpansion which has been seen when films are irradiated with bandgap light. Our results also show that this photovaporization is accompanied by the formation of $S$-rich surface layer. The latter result is important for optimizing parameters of photolithographic processes on $A s$-based $\mathrm{ChG}$ thin films [27].

In order to choose the physically real mechanisms out of the whole variety of possible photovaporization routes, the energies of possible precursors and products of photoreactions have been calculated (Table 3, Fig. 8). In turn, these energies were used to estimate the balance of photoreactions involving relevant complexes and molecules (Table 4). Owing to the obtained XPS results, showing the increase in $S / A s$ ratio and disappearance of homopolar bonds after irradiation as well as the Raman data, showing disappearance of distinguished modes associated with Asbased cage molecules, we have restricted our analysis to the possible decomposition reactions 
involving As-rich cage-like molecules (Tables 4). As it can be seen from the performed calculations, the most of the reactions are energetically favorable if $A s_{4} S_{3}$ cage molecule is formed as a result of photoreaction. So, it can be argued that photovaporization of these molecules (intrinsic mechanism) along with photooxidation (extrinsic) mechanism according to the reaction (1) are responsible for the changes in $S / A s$ ratio on the surface of thermally evaporated $A s_{40} S_{60}$ thin films. Of course, the reactions in Table 4 could have different activation barriers and proceed with different effectiveness. Nevertheless, we suggest the whole intrinsic mechanism of photovaporization in $A s_{40} S_{60}$ thin film to look like follows: we start from network $A s S_{3 / 2}$ clusters and $A s$ rich cage-like molecules; superbandgap light breaks the bonds and triggers number of the reactions including those presented in Table 4, leading to the excessive formation of $A s_{4} S_{3}$ cage molecules on the surface of the film; the local increase in temperature due to the thermalization of hot electrons excited by superbangap light causes volatilization of these molecules, which are kept only by weak van der Waals forces at the surface. Obviously, these processes should weaken when the energy of irradiation decreases, just explaining the absence of changes in S/As ratio under the exposure to the light of $>450 \mathrm{~nm}$ wavelengths.

The mechanism in $S$-rich $A s_{x} S_{100-x}$ thin films is even more complicated, owing to photo-induced physical aging, possibility of photodiffusion, etc., and would be a subject of our further detail analysis.

\section{Conclusions}

The present results show that irradiation of ChG thin films of $A s_{x} S_{100-x}(x=30,33,35,40)$ system with UV light both in air and argon atmosphere leads to formation of $S$-rich surface layer. We conclude that different types of As-rich cage-like molecules, both oxide and non-oxide, are photovaporized from the surface of thermally-deposited $A s_{40} S_{6} 60$ thin film. Using high-sensitivity LEIS measurements we exclude photoinduced diffusion in this composition as a possible mechanism of the observed chemical modification of the surfaces. High resolution XPS as well as quantum chemistry calculations helped propose atomistic mechanism of the observed photostructural transformations, with the XPS measurements identifying chemical environments of $A s$ and $S$ atoms before and after irradiation.

\section{Acknowledgements}

The authors thank U.S. National Science Foundation, through International Materials Institute for New Functionality in Glass (Grant No. DMR-0844014), for initiating the international collaboration and providing financial support for this work. The group from Austin Peay State University acknowledges financial support from NSF Grant DMR-1409160. Both these NSF

grants allowed us to develop a recognizable undergraduate research program which contributed to current publication. Furthermore calculations were run on APSU's cluster, which was purchased under NSF Grant CNS-0722890. The authors would like to thank also Dr. Henry Luftman from Lehigh University for help with LEIS measurements. 


\section{References}

[1] A. Zakery, S. R. Elliott, Optical properties and applications of chalcogenide glasses: a review, J. Non-Cryst. Solids 330 (2003) 1-12.

[2] M. Frumar, T. Wagner, Ag doped chalcogenide glasses and their application, Curr. Opin. Solid St. M. 7 (2003) 117-126.

[3] Ke. Tanaka, Photoinduced processes in chalcogenide glasses, Curr. Opin. Solid St. M. 1 (1996) 567-571.

[4] A. Seddon, Chalcogenide glasses: a review of their preparation, properties and applications, J. Non-Cryst. Solids 184 (1995) 44-50.

[5] Tanaka K, Shimakawa K. Amorphous Chalcogenide Semiconductors and Related Materials. New York, Dordrecht, Heidelberg, London: Springer; 2011.

[6] P. Nagels, L. Tichy, R. Mertens, R. Callaerts, Low-temperature photodarkening of the $\mathrm{As}_{\mathrm{x}} \mathrm{Se}_{100-\mathrm{x}}$ system prepared by PECVD. Mater. Lett. 46 (2000) 234-238.

[7] M. Stuchlik, S. R. Elliott, All-optical actuation of amorphous chalcogenide-coated cantilevers, J. Non-Cryst. Solids 353 (2007) 250-262.

[8] A. Kozdras, R. Golovchak, O. Shpotyuk, S. Szymura, A. Saiter, J.-M. Saiter, Light-assisted physical aging in chalcogenide glasses: Dependence on the wavelength of incident photons, J. Mater. Res. 26 (2011) 2420-2437.

[9] A. V. Kolobov, J. P. S. Badyal, R. M. Lambert, Novel photoinduced surface oxidation of an amorphous semiconductor: An XPS study of vitreous arsenic sulphide, Surf. Sci. 222 (1989) L819-L824.

[10] R. Chauhan, A. K. Srivastava, A. Tripathi, K. K. Srivastava, Linear and nonlinear optical changes in amorphous $\mathrm{As}_{2} \mathrm{Se}_{3}$ thin film upon UV exposure, Progr. Nat. Sci. 21 (2011) 205-210. [11] M. Janai, Photolithographic processes in amorphous semiconductors, J. Phys. Colloq. 42 (C4) (1981) 1105-1114.

[12] Ke. Tanaka, Spectral dependence of photoexpansion in $\mathrm{As}_{2} \mathrm{~S}_{3}$ glass, Philos. Mag. Lett. 79 (1999) 25-30.

[13] H. Fritzsche, The origin of reversible and irreversible photostructural changes in chalcogenide glasses, Philos. Mag. B 68 (1993) 561-572.

[14] A. Kovalskiy, M. Vlcek, K. Palka, R. Golovchak, H. Jain, Wavelength dependence of photostructural transformations in $\mathrm{As}_{2} \mathrm{~S}_{3}$ thin films, Physics Procedia 44 (2013) 75-81.

[15] H. H. Brongersma, M. Draxler, M. de Ridder, P. Bauer, Surface composition analysis by low-energy ion scattering, Surf. Sci. Rep. 62 (2007) 63-109.

[16] R. Golovchak, O. Shpotyuk, A. Kovalskiy, A. C. Miller, J. Cech, H. Jain, Coordination defects in bismuth-modified arsenic selenide glasses: High-resolution X-ray photoelectron spectroscopy measurements, Phys. Rev. B 77 (2008) 172201-4.

[17] O. Shpotyuk, M. Hyla, V. Boyko, Structural-topological genesis of network-forming nanoclusters in chalcogenide semiconductor glasses, J. Optoelectron. Adv. M. 15 (2013) 14291437.

[18] O. Shpotyuk, M. Hyla, V. Boyko, Compositionally-dependent structural variations in glassy chalcogenides: The case of binary As-Se system, Comp. Mater. Sci. 110 (2015) 144-151.

[19] M. Valiev, E. J. Bylaska, N. Govind, K. Kowalski, T. P. Straatsma, H. J .J. van Dam, D. Wang, J. Nieplocha, E. Apra, T. L. Windus, W. A. de Jong, NWChem: a comprehensive and scalable open-source solution for large scale molecular simulations, Comput. Phys. Commun. 181 (2010) 1477-1489. 
[20] R. Krishnan, J. S. Binkley, R. Seeger, J. A. Pople, Selfconsistent molecular orbital methods. XX. A basis set for correlated wave functions, J. Chem. Phys. 72 (1980) 650-654.

[21] A. D. McLean, G. S. Chandler, Contracted Gaussian basis sets for molecular calculations. I. Second row atoms, Z=11-18, J. Chem. Phys. 72 (1980) 5639-5648.

[22] L. A. Curtiss, M. P. McGrath, J-P. Blandeau, N. E. Davis, R. C. Binning, Jr., L. Radom, Extension of Gaussian- 2 theory to molecules containing third- row atoms Ga-Kr, J. Chem. Phys. 103 (1995) 6104-6113.

[23] A. T. Wong, R. J. Harrison, Approaches to large-scale parallel self-consistent field calculation, J. Comp. Chem. 16 (1995) 1291-1300.

[24] I. T. Foster, J. L. Tilson, A. F. Wagner, R. L. Shepard, R. J. Harrison, R. A. Kendall, R. J. Littlefield, Toward high-performance computational chemistry: I. Scalable Fock matrix construction algorithms, J. Comp. Chem. 17 (1996) 109-123.

[25] C. Adamo, V. Barone, Toward reliable density functional methods without adjustable parameters: The PBE0 model, J. Chem. Phys. 110 (1999) 6158-6170.

[26] C. Møller, M. S. Plesset, Note on an approximation treatment for many-electron systems, Physical Review 46 (1934) 618-622.

[27] A. Kovalskiy, M. Vlcek, J. Cech, W. R. Heffner, C. M. Waits, M. Dubey, H. Jain, Chalcogenide glass e-beam and photo resists for ultrathin grayscale patterning, $\mathrm{J}$.

Micro/Nanolithogr. MEMS MOEMS 8 (2009) 043012-1-11.

[28] R. M. Almeida, H. Jain, C. G. Pantano, Low-energy ion-scattering spectroscopy of modified silicate glasses, J. Am. Ceram. Soc. (2016) doi: 10.1111/jace.14126.

[29] A. Kovalskiy, R. Golovchak, M. Vlcek, H. Jain, Electronic and atomic structure of amorphous thin films with high-resolution XPS: Examples of applications \& limitations, J. NonCryst. Solids 377 (2013) 155-158.

[30] J. S. Berkes, S. W. Ing, W. J. Hillegas, Photodecomposition of amorphous $\mathrm{As}_{2} \mathrm{Se}_{3}$ and $\mathrm{As}_{2} \mathrm{~S}_{3}$, J. Appl. Phys. 42 (1971) 4908-4916.

[31] A. J. Lowe, S. R. Elliott, G. N. Greaves, Extended X-ray absorption fine-structure spectroscopy study of photostructural changes in amorphous arsenic chalcogenides, Philos. Mag. B 54 (1986) 483-490.

[32] A. V. Kolobov, J. Tominaga, Chalcogenide glasses in optical recording: recent progress. J. 8 Optolectron. Adv. M. 4 (2002) 679-686.

[33] P. Lucas, E. A. King, A. Doraiswamy, P. Jivaganont, Competitive photostructural effects in Ge-Se glass, Phys. Rev. B 71 (2005) 104207.

[34] R. Golovchak, O. Shpotyuk, J. S. McCloy, B. Riley, C. F. Windisch, S. K. Sundaram, A. Kovalskiy, H. Jain, Structural model of homogeneous As-S glasses derived from Raman spectroscopy and high-resolution XPS. Philos. Mag. 90 (2010) 4489-4501.

[35] J. T. Bloking, S. Krishnaswami, H. Jain, M. Vlcek, R. P. Vinci, Photoinduced changes in the surface morphology of As ${ }_{50} \mathrm{Se}_{50}$ chalcogenide glass films, Opt. Mater. 17 (2001) 453-458.

[36] M. P. Trubisky, J. H. Neyhart, Aging of vitreous arsenic-selenium photoconductors, Appl. Optics 8 (1969) 59-63.

[37] T. M. Donovan, A. D. Baer, J. H. Dancy, J. O. Porteus, Defects and impurities in $\mathrm{As}_{2} \mathrm{~S}_{3}$, $\mathrm{As}_{2} \mathrm{Se}_{3}$ and $\mathrm{NaF}$ coatings. In: Laser Induced Damage in Optical Materials. 1977. ASTM STP, (655).

[38] P. Bonazzi, L. Bindi, G. Pratesi, S. Menchetti, Light-induced changes in molecular arsenic sulfides: State of the art and new evidence by single-crystal X-ray diffraction, Am. Mineral. 91 (2006) 1323-1330. 


\section{Figure captions}

Fig. 1. $S 2 p(a)$ and $A s 3 d(b)$ XPS core level spectra of virgin thermally evaporated $A s 40 S_{60}$ thin films

Fig. 2. Comparison of $S 2 p$ XPS core level spectra for virgin and irradiated in air at $W=100$ $\mathrm{mW} / \mathrm{cm}^{2}$ As $40 S_{60}$ thin films

Fig. 3. $S 2 p$ XPS core level spectra of virgin $(a)$ and irradiated in argon at $W=100 \mathrm{~mW} / \mathrm{cm}^{2}(b, c)$ $A s_{40} S_{60}$ thin films

Fig. 4. As $3 d$ XPS core level spectra of virgin $(a)$ and irradiated in argon at $W=100 \mathrm{~mW} / \mathrm{cm}^{2}(b, c)$ As $40 S_{60}$ thin films

Fig. 5. Comparison of $O 1 s$ XPS core level spectra for $A s_{40} S_{60}$ thin films irradiated in air and argon with $375 \mathrm{~nm}$ LED at $W=100 \mathrm{~mW} / \mathrm{cm}^{2}$

Fig. 6. Raman spectra of virgin and irradiated in argon at $W=100 \mathrm{~mW} / \mathrm{cm}^{2} A s_{40} S_{60}$ thin films

Fig. 7. In-depth compositional profile for $A s_{40} S_{60}$ thin films preliminarily irradiated in argon with $375 \mathrm{~nm}$ LED at $W=100 \mathrm{~mW} / \mathrm{cm}^{2}$

Fig. 8. Ball-stick diagrams showing geometrically optimized configurations of some clusters in binary $A s-S$ system (red and yellow balls stand for $A s$ and $S$ atoms, respectively): network $A s_{2} S_{3}$ cluster typical for mineral orpiment ( $a$, the boundary sulfur atoms are terminated by grey-colored hydrogen atoms), cage-like molecular clusters typical for mineral uzonite $A s_{4} S_{5}(b)$, realgar $A s_{4} S_{4}$ $(c)$, pararealgar $A s_{4} S_{4}(d)$, dimorphite $A s_{4} S_{3}(e)$, duranusite $A s_{4} S(f)$ and pure $A s_{4}(g)$. 
a

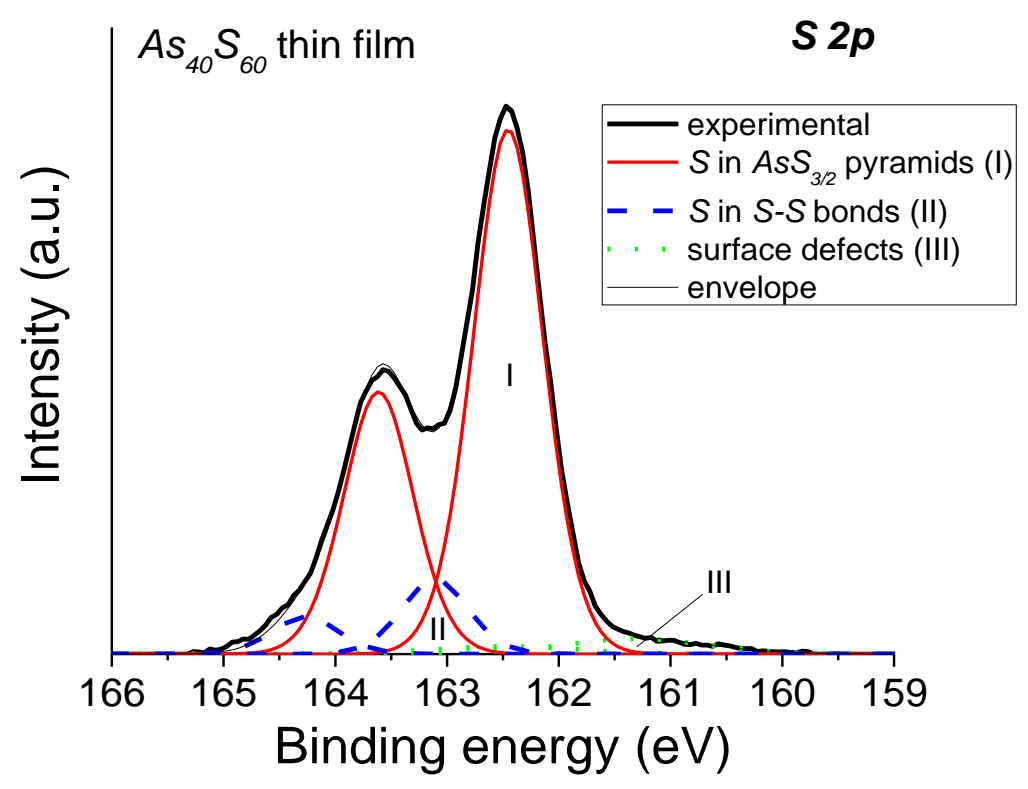

Fig. 1a 


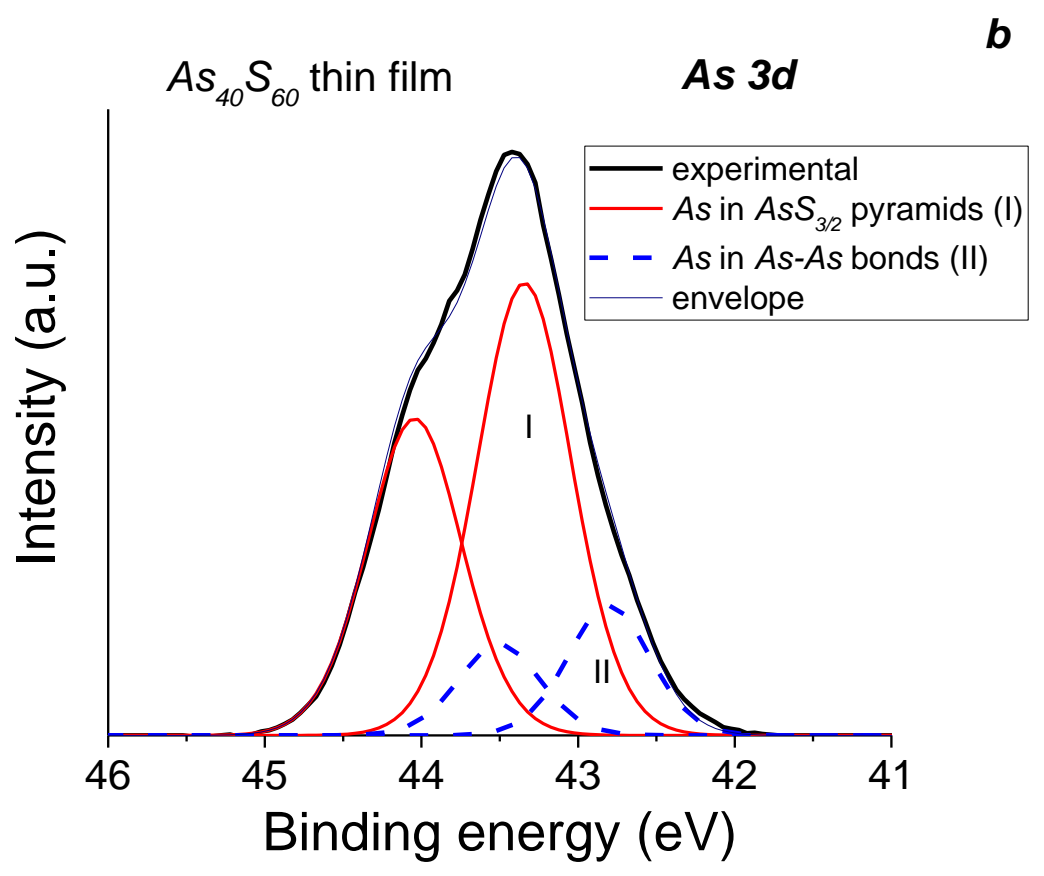

Fig. 1b 


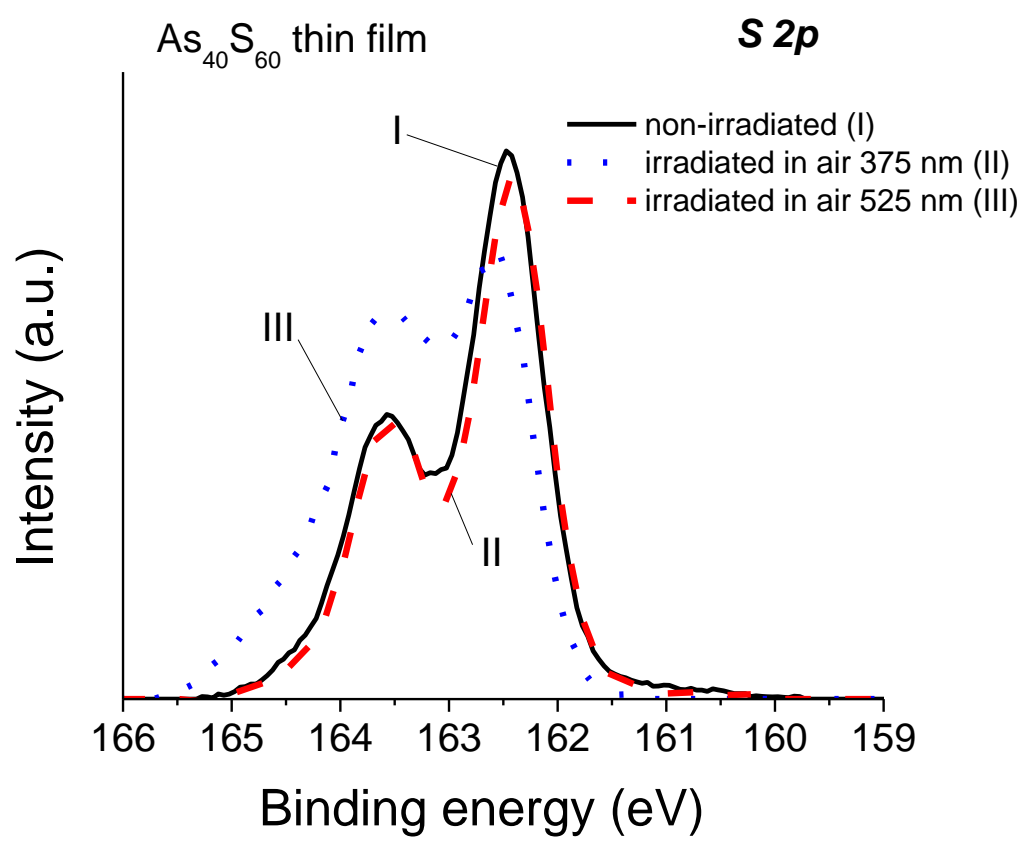

Fig. 2 


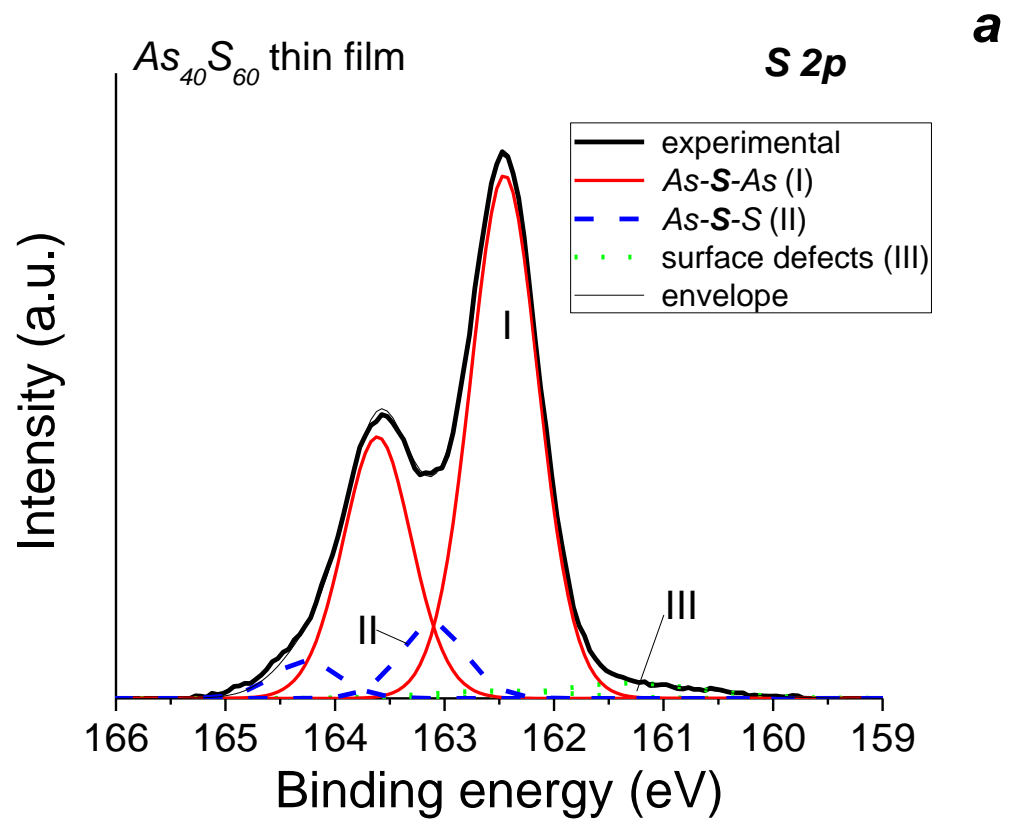

Fig. 3a 


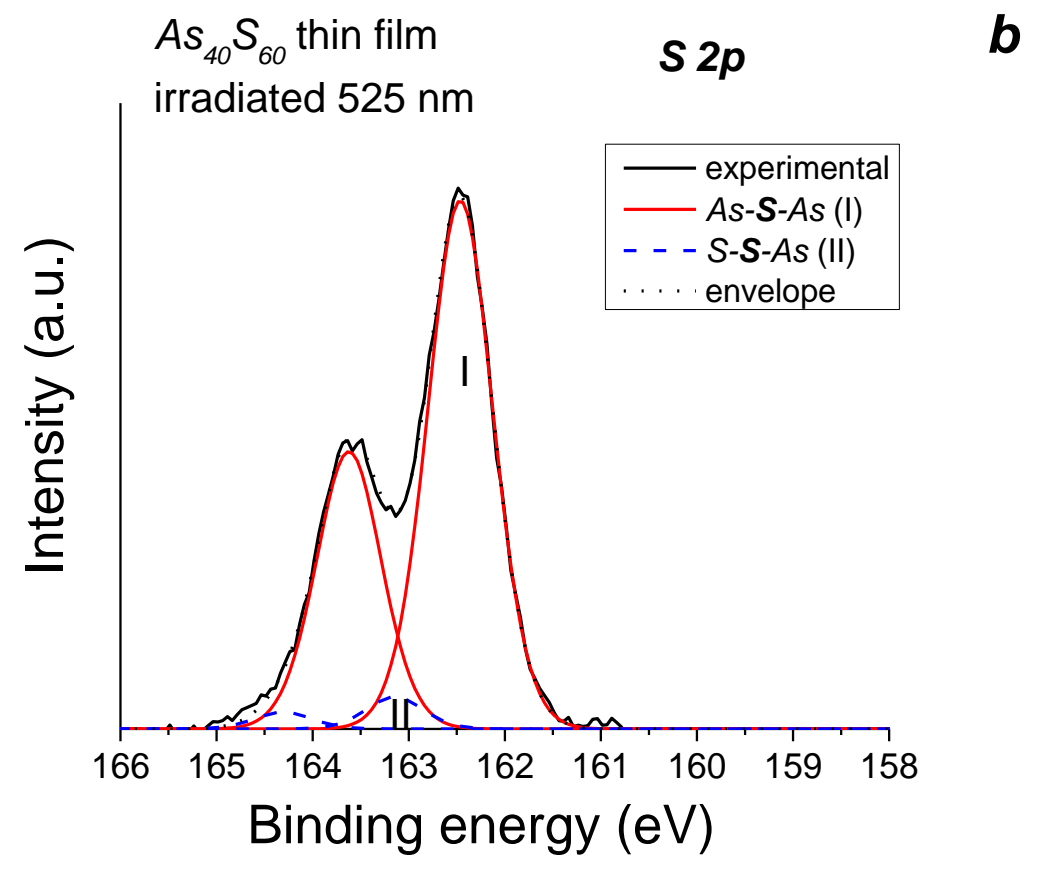

Fig. 3b 


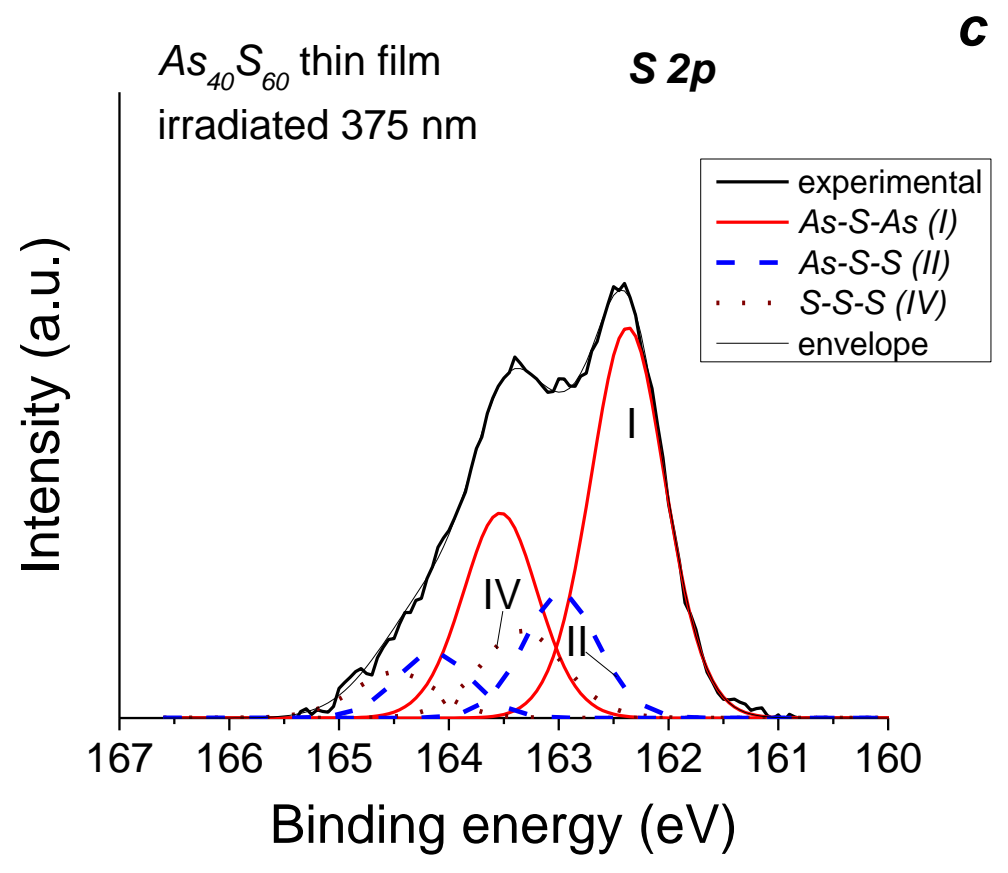

Fig. 3c 


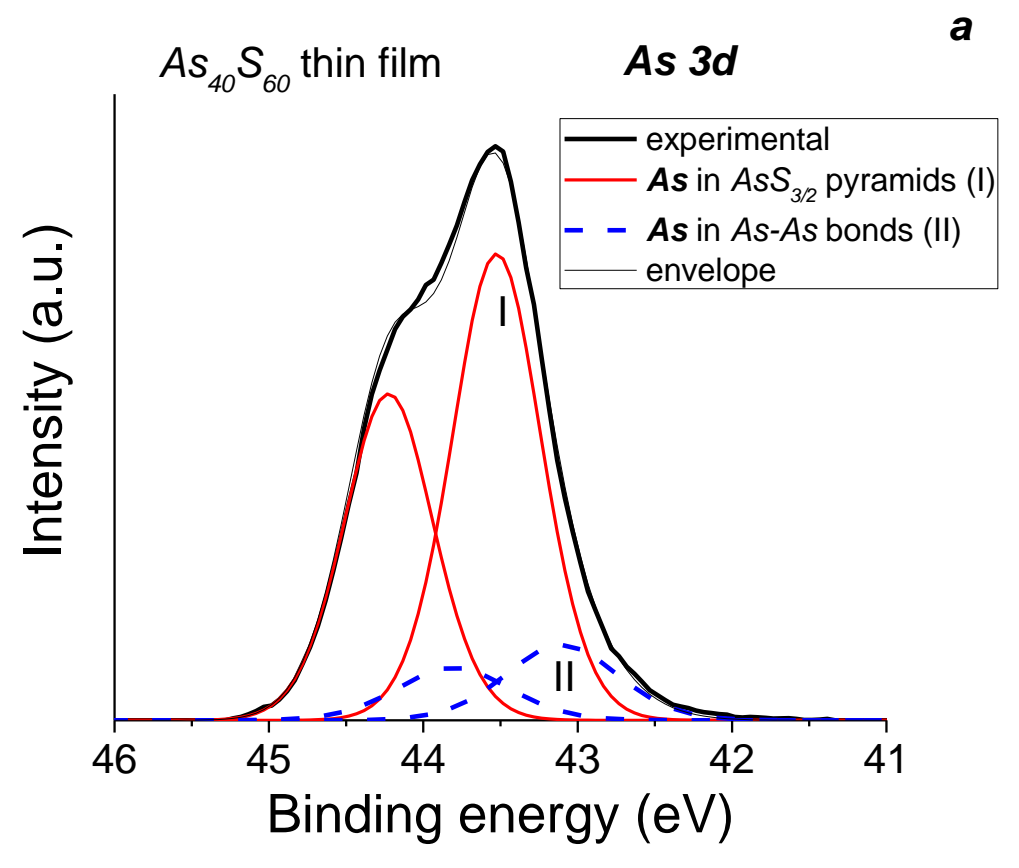

Fig. 4a 


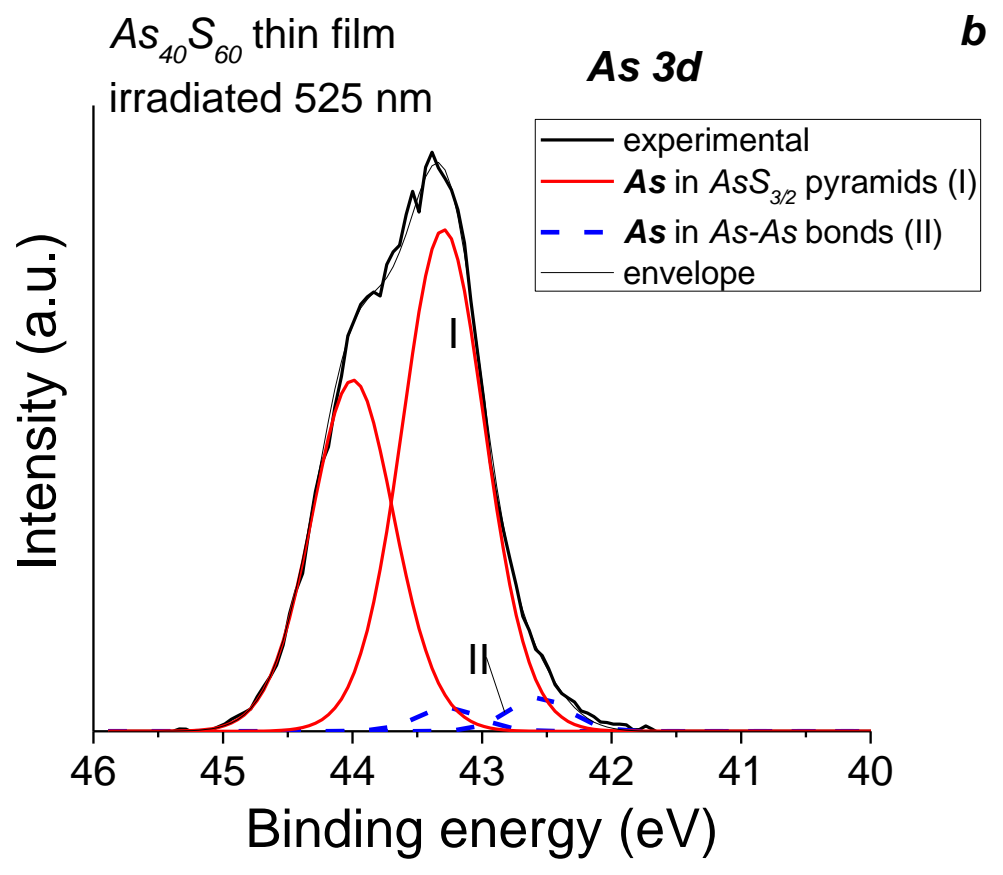

Fig. 4b 


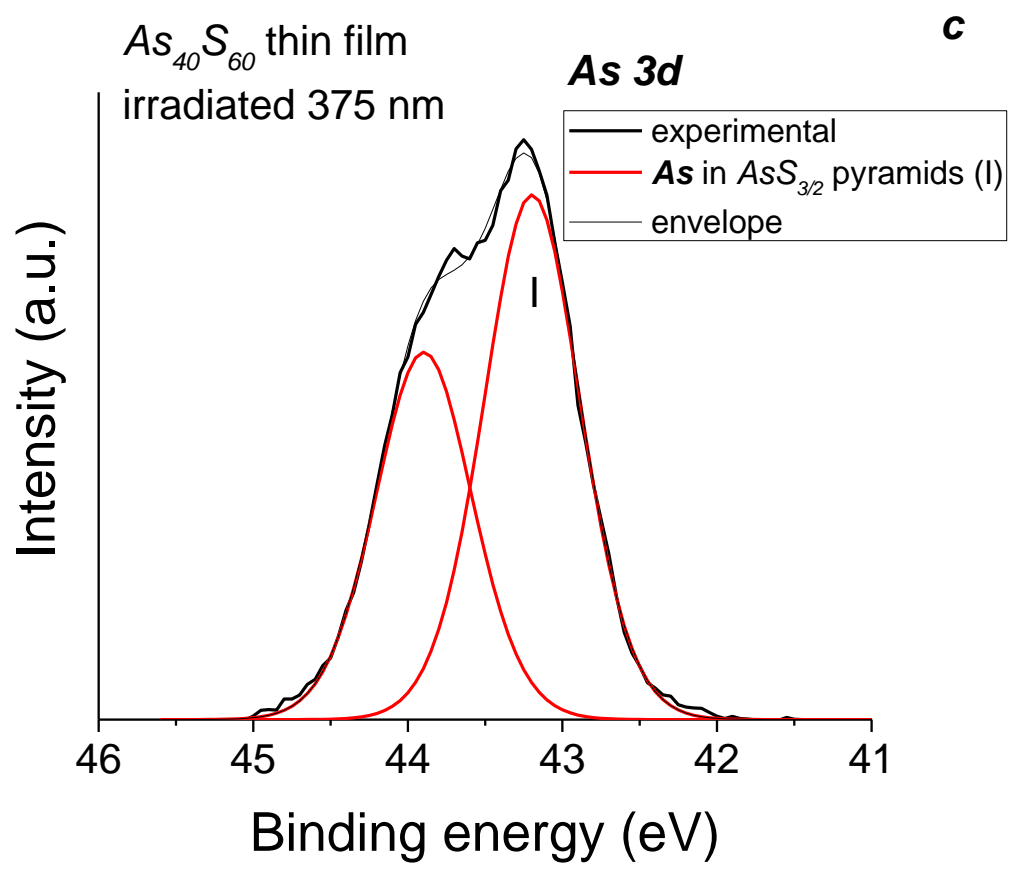

Fig. 4c 


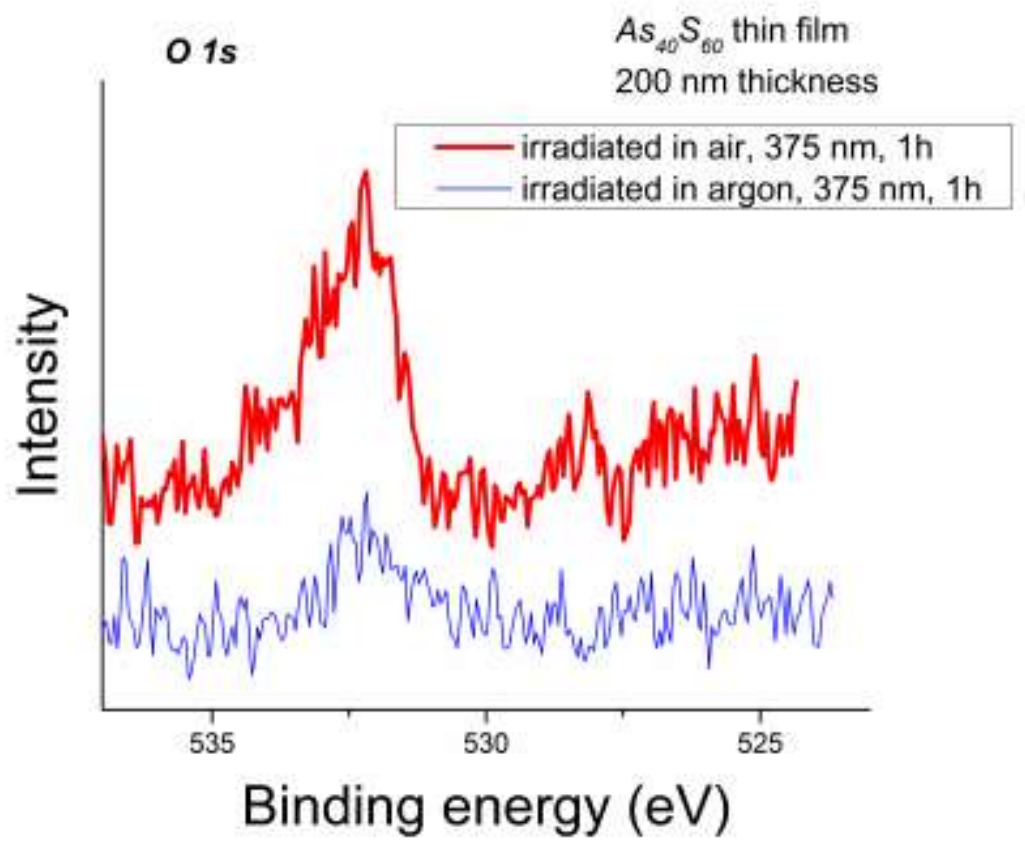

Fig. 5 


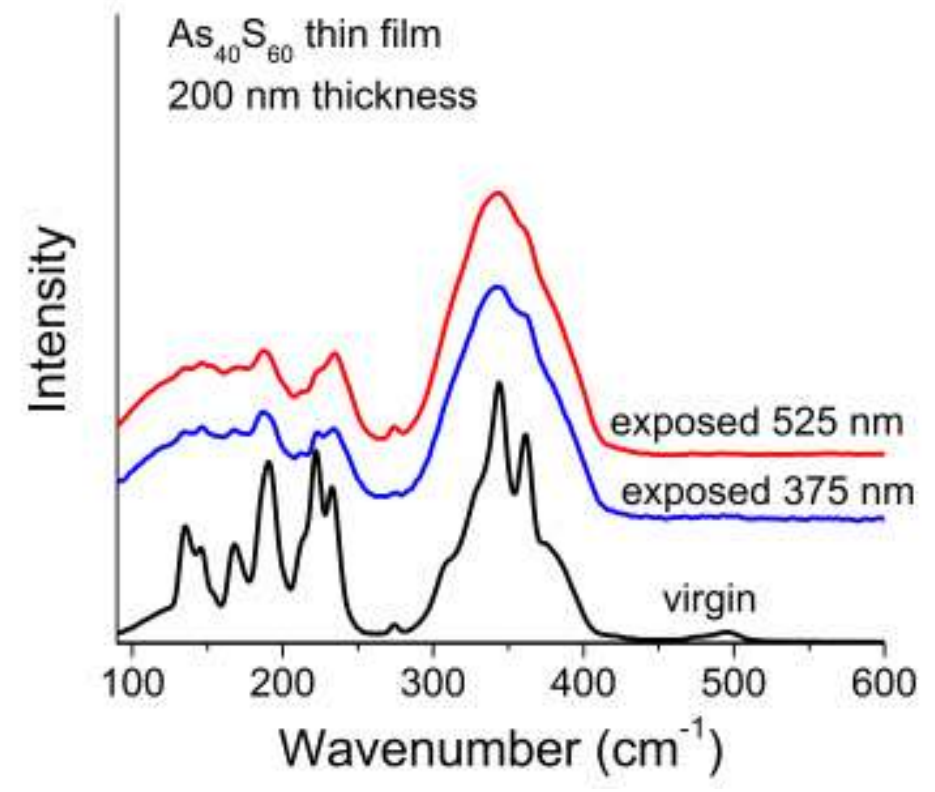

Fig. 6 


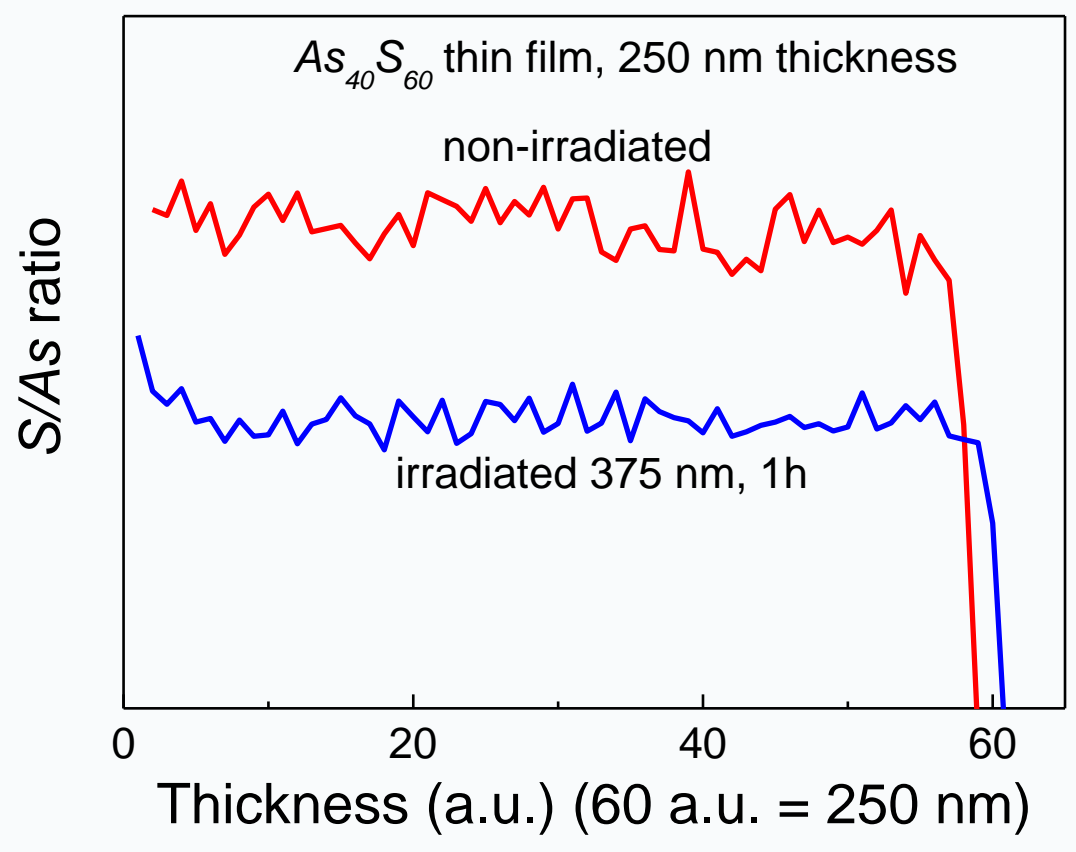

Fig. 7 


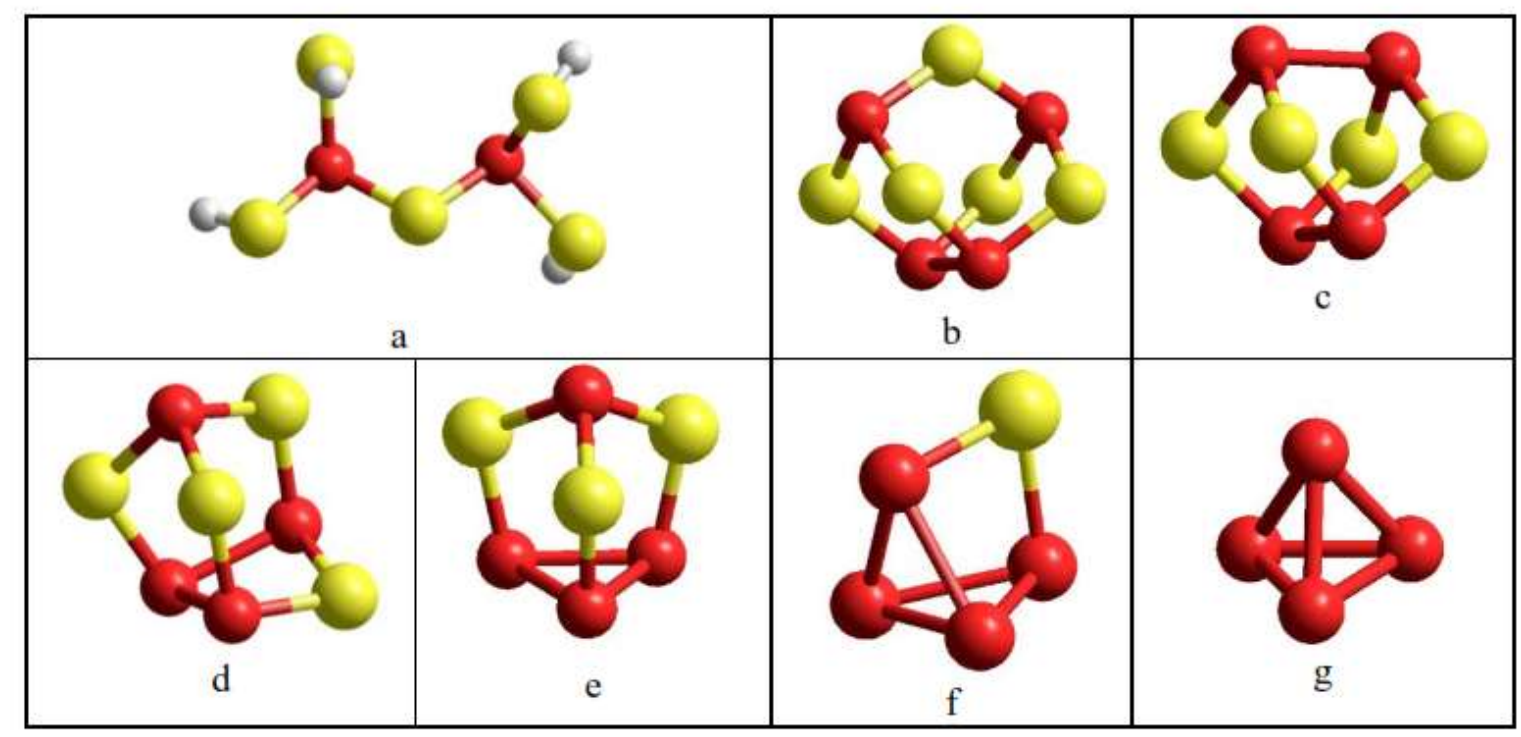

Fig. 8 
Table 1. Comparison of the chemical composition of the surface for $A s_{40} S_{60} \mathrm{ChG}$ thin films irradiated in air and argon atmospheres with LED light of different wavelengths

$$
\left(W \approx 100 \mathrm{~mW} / \mathrm{cm}^{2}\right)
$$

\begin{tabular}{|c|c|c|c|c|c|c|c|c|}
\hline \multicolumn{9}{|c|}{$A s_{40} S_{60}$} \\
\hline & \multicolumn{3}{|c|}{ Air } & \multicolumn{5}{|c|}{ Argon } \\
\hline & As & $S$ & $O$ & \multirow{2}{*}{ S/As } & As & $S$ & $O$ & \multirow{2}{*}{$S / A s$} \\
\hline & \multicolumn{3}{|c|}{ at. $\%$} & & \multicolumn{3}{|c|}{ at. $\%$} & \\
\hline $375 \mathrm{~nm}$ & 31 & 65 & 4 & $68 / 32$ & 30 & 64 & 6 & $68 / 32$ \\
\hline $405 \mathrm{~nm}$ & 30 & 65 & 6 & $69 / 31$ & 32 & 63 & 5 & $67 / 33$ \\
\hline $450 \mathrm{~nm}$ & 35 & 62 & 3 & $64 / 36$ & 36 & 60 & 4 & $62 / 38$ \\
\hline $525 \mathrm{~nm}$ & 37 & 60 & 3 & $62 / 38$ & 36 & 58 & 6 & $62 / 38$ \\
\hline virgin & 37 & 60 & 3 & $62 / 38$ & 39 & 58 & 3 & $60 / 40$ \\
\hline
\end{tabular}


Table 2. Chemical composition of the surface for different arsenic sulfide $\mathrm{ChG}$ thin films irradiated in argon atmosphere with LED light of different wavelengths $\left(W \approx 100 \mathrm{~mW} / \mathrm{cm}^{2}\right)$

\begin{tabular}{|c|c|c|c|c|c|c|c|c|}
\hline \multirow{2}{*}{ Sample } & \multicolumn{2}{|c|}{$A s_{30} S_{70}$} & \multicolumn{2}{|c|}{$A s_{33} S_{67}$} & \multicolumn{2}{|c|}{$A s_{35} S_{65}$} & \multicolumn{2}{|c|}{$A s_{40} S_{60}$} \\
\hline & \multicolumn{8}{|c|}{$A s, S($ at. $\%)$} \\
\hline $375 \mathrm{~nm}$ & 26 & 74 & 29 & 71 & 29 & 71 & 32 & 68 \\
\hline $405 \mathrm{~nm}$ & 27 & 73 & 30 & 70 & 30 & 70 & 33 & 67 \\
\hline $450 \mathrm{~nm}$ & 31 & 69 & 31 & 69 & 34 & 66 & 38 & 62 \\
\hline $525 \mathrm{~nm}$ & 31 & 69 & 33 & 67 & 35 & 65 & 38 & 62 \\
\hline virgin & 31 & 69 & 33 & 67 & 35 & 65 & 40 & 60 \\
\hline
\end{tabular}


Table 3. The calculated electronic energies for different molecular clusters possible in overstoichiometric $A s-S \mathrm{ChG}$, as well as the molecules used to calculate the energy of the As2S3 molecular cluster via CINCA.

\begin{tabular}{lccc}
\hline Calculated Structure & $\begin{array}{c}\text { E }(\mathbf{M P 2 / 6 - 3 1 1 G} * *) \\
(\mathrm{kcal} / \mathrm{mol})\end{array}$ & $\begin{array}{c}\text { E(PBE0/6-311G**) } \\
(\mathrm{kcal} / \mathrm{mol})\end{array}$ & $\begin{array}{c}\text { E(HF/6-311G**) } \\
(\mathrm{kcal} / \mathrm{mol})\end{array}$ \\
\hline $\mathrm{SH}_{2}$ (not shown) & -250356 & -250537 & -250188 \\
\hline $\mathrm{As}_{2} \mathrm{~S}_{5} \mathrm{H}_{4}$ (Fig. 8a) & -4054151 & -4056200 & -4052721 \\
\hline $\mathrm{As}_{4} \mathrm{~S}_{5}$, Uzonite (Fig. 8b) & -6857261 & -6860450 & -6855223 \\
\hline $\mathrm{As} \mathrm{S}_{4},(\alpha / \beta)--$ Realgar (Fig. 8c) & -6607644 & -6610654 & -6605758 \\
\hline $\mathrm{As}_{4} \mathrm{~S}_{4}$, Para-Realgar (Fig. 8d) & -6607636 & -6610649 & -6605755 \\
\hline $\mathrm{As}_{4} \mathrm{~S}_{3}$, Dimorphite (Fig. 8e) & -6358020 & -6360852 & -6356289 \\
\hline $\mathrm{As}_{4} \mathrm{~S}$, Duranusite (Fig. 8f) & -5858741 & -5861223 & -5857328 \\
\hline $\mathrm{As}_{4}($ Fig. 8g) & -5609135 & -5611436 & -5607873 \\
\hline $\mathrm{As}_{2} \mathrm{~S}_{3}$ (via CINCA) & -3553437 & -3555124 & -3552344 \\
\hline
\end{tabular}


Table 4. $\Delta E /$ particle (products - reactants) of decomposition reactions possible in the studied thin films. Of particular note is that all presented pathways are energetically favorable (negative $\Delta E /$ particle values).

\begin{tabular}{|c|c|c|c|}
\hline & MP2/6-311G** & PBE0/6-311G** & HF/6-311G** \\
\hline Reaction & (kcal/mol) & $(\mathrm{kcal} / \mathrm{mol})$ & $(\mathrm{kcal} / \mathrm{mol})$ \\
\hline $4 \mathrm{As}_{4} \mathrm{~S}_{5}+\mathrm{As}_{4} \rightarrow 5 \mathrm{p}-\mathrm{As}_{4} \mathrm{~S}_{4}$ & -0.109 & -0.291 & -0.235 \\
\hline $3 \mathrm{p}-\mathrm{As}_{4} \mathrm{~S}_{4} \rightarrow 2 \mathrm{As}_{2} \mathrm{~S}_{3}+2 \mathrm{As}_{4} \mathrm{~S}_{3}$ & -0.223 & -0.260 & 0.001 \\
\hline $3(\alpha / \beta)-\mathrm{As}_{4} \mathrm{~S}_{4}+\mathrm{As}_{4} \rightarrow 4 \mathrm{As}_{4} \mathrm{~S}_{3}$ & -0.442 & -0.470 & -0.308 \\
\hline $2 \mathrm{p}-\mathrm{As}_{4} \mathrm{~S}_{4}-->\mathrm{As}_{4} \mathrm{~S}_{5}+\mathrm{As}_{4} \mathrm{~S}_{3}$ & -0.504 & -0.227 & -0.123 \\
\hline $\mathrm{As}_{4} \mathrm{~S}_{5}+\mathrm{As}_{4} \mathrm{~S}_{3} \rightarrow 2(\alpha / \beta)-\mathrm{As}_{4} \mathrm{~S}_{4}$ & -0.506 & -0.314 & -0.238 \\
\hline $3 \mathrm{As}_{4} \mathrm{~S}_{5}+\mathrm{As}_{4} \mathrm{~S} \rightarrow 4 \mathrm{p}-\mathrm{As}_{4} \mathrm{~S}_{4}$ & -0.700 & -0.765 & -0.702 \\
\hline $2 \mathrm{As}_{2} \mathrm{~S}_{3}+2 \mathrm{As}_{4} \mathrm{~S}_{3} \rightarrow 3(\alpha / \beta)-\mathrm{As}_{4} \mathrm{~S}_{4}$ & -0.787 & -0.281 & -0.362 \\
\hline $\mathrm{p}-\mathrm{As}_{4} \mathrm{~S}_{4} \rightarrow(\alpha / \beta)-\mathrm{As}_{4} \mathrm{~S}_{4}$ & -1.010 & -0.542 & 0.361 \\
\hline $4 \mathrm{As}_{2} \mathrm{~S}_{3}+\mathrm{As}_{4} \rightarrow 3 \mathrm{p}-\mathrm{As}_{4} \mathrm{~S}_{4}$ & -1.080 & -0.569 & -0.722 \\
\hline $4 \mathrm{As}_{4} \mathrm{~S}_{5}+\mathrm{As}_{4} \rightarrow 5(\alpha / \beta)-\mathrm{As}_{4} \mathrm{~S}_{4}$ & -1.118 & -0.832 & -0.597 \\
\hline $3 \mathrm{p}-\mathrm{As}_{4} \mathrm{~S}_{4}+\mathrm{As}_{4} \rightarrow 4 \mathrm{As}_{4} \mathrm{~S}_{3}$ & -1.307 & -0.935 & -0.617 \\
\hline $3 \mathrm{As}_{4} \mathrm{~S}_{5}+2 \mathrm{As}_{4} \rightarrow 5 \mathrm{As}_{4} \mathrm{~S}_{3}$ & -1.400 & -1.184 & -0.819 \\
\hline $2(\alpha / \beta)-\mathrm{As}_{4} \mathrm{~S}_{4}+\mathrm{As}_{4} \mathrm{~S} \rightarrow 3 \mathrm{As}_{4} \mathrm{~S}_{3}$ & -1.449 & -1.273 & -1.075 \\
\hline $3 \mathrm{As}_{4} \mathrm{~S}_{5}+\mathrm{As}_{4} \mathrm{~S} \rightarrow 4(\alpha / \beta)-\mathrm{As}_{4} \mathrm{~S}_{4}$ & -1.709 & -1.307 & -1.063 \\
\hline $6 \mathrm{As}_{2} \mathrm{~S}_{3}+2 \mathrm{As}_{4} \mathrm{~S} \rightarrow 5 \mathrm{p}-\mathrm{As}_{4} \mathrm{~S}_{4}$ & -1.929 & -1.301 & -1.420 \\
\hline $4 \mathrm{As}_{2} \mathrm{~S}_{3}+\mathrm{As}_{4} \rightarrow 3(\alpha / \beta)-\mathrm{As}_{4} \mathrm{~S}_{4}$ & -2.090 & -1.111 & -1.083 \\
\hline $2 \mathrm{p}-\mathrm{As}_{4} \mathrm{~S}_{4}+\mathrm{As}_{4} \mathrm{~S} \rightarrow 3 \mathrm{As}_{4} \mathrm{~S}_{3}$ & -2.218 & -1.686 & -1.351 \\
\hline $2 \mathrm{As}_{2} \mathrm{~S}_{3}+\mathrm{As}_{4} \rightarrow 2 \mathrm{As}_{4} \mathrm{~S}_{3}$ & -2.233 & -1.423 & -1.236 \\
\hline $\mathrm{As}_{2} \mathrm{~S}_{5}+\mathrm{As}_{4} \mathrm{~S} \rightarrow 2 \mathrm{As}_{4} \mathrm{~S}_{3}$ & -2.751 & -2.269 & -1.885 \\
\hline $6 \mathrm{As}_{2} \mathrm{~S}_{3}+2 \mathrm{As}_{4} \mathrm{~S} \rightarrow 5(\alpha / \beta)-\mathrm{As}_{4} \mathrm{~S}_{4}$ & -2.938 & -1.843 & -1.781 \\
\hline $4 \mathrm{As}_{2} \mathrm{~S}_{3}+3 \mathrm{As}_{4} \mathrm{~S} \rightarrow 5 \mathrm{As}_{4} \mathrm{~S}_{3}$ & -3.688 & -2.677 & -2.432 \\
\hline
\end{tabular}

